\title{
PENYULUHAN DAN PELATIHAN HIPNOBREASTFEEDING PADA IBU MENYUSU DALAM MENINGKATKAN PRODUKSI ASI
}

\author{
Julietta Hutabarat ${ }^{1 凶}$, Sartini Bangun ${ }^{2}$ \\ Coreponding author: julietta.hutabarat68@gmail.com \\ ${ }^{1,2}$ Jurusan Kebidanan, Poltekkes Kemenkes Medan, Indonesia
}

Genesis Naskah: Submitted: 10-07-2021, Revised: 16-07-2021, Accepted: 19-07-2021

\begin{abstract}
Abstrak
ASI merupakan zat gizi yang dibutuhkan dalam proses pertumbuhan dan perkembangan bayi yang dipantau melalui penambahan berat badan sesuai kurva tumbuh kembang. Apabila produksi ASI cukup dapat menghantar bayi mendapatkan ASI secara eksklusif. Persentase pemberian ASI Eksklusif masih rendah. Cakupan bayi mendapat ASI Eksklusif di Provinsi Sumatera Utara 12,4\%, masih di bawah target nasional yaitu 80\%. Alasan utama penyebab kegagalan pemberian ASI Eksklusif adalah produksi ASI sedikit. Produksi ASI dipengaruhi hormon prolaktin dan oksitosin yang sangat dipengaruhi kondisi psikologis ibu. Semakin ibu tenang dan percaya diri maka kedua hormon ini semakin banyak diproduksi Faktor psikologis berpengaruh $70 \%$ terhadap produksi ASI. Hypnobreastfeeding adalah upaya alami menggunakan energi bawah sadar dengan memasukkan kalimat afirmasi positif sehingga keadaan ibu rileks dan mampu menghasilkan ASI yang cukup. Pengabdian masyarakat bertujuan memberikan penyuluhan dan pelatihan Hypnobreastfeeding pada 19 ibu menyusu dalam meningkatkan produksi ASI di Dusun III dan V Desa Namo Bintang Kecamatan Pancur Batu Kabupaten Deli Serdang. Setelah dilakukan penyuluhan terjadi peningkatan pengetahuan ibu $52.6 \%$ kategori baik dimana sebelumnya $68.4 \%$ pengetahuan pada kategori kurang. Dan setelah 2 minggu ibu melakukan hypnobreastfeeding terdapat peningkatan rerata BB bayi sebesar 339,4 gr. Relaksasi yang dilakukan dengan teratur mampu menyeimbangkan kadar hormone dan mendukung produksi ASI serta membentuk pola pikir yang positif dan ketenangan untuk menyusui, sehingga ibu dapat menikmati proses menyusui dengan baik.
\end{abstract}

Kata Kunci : Hypnobreastfeeding, Produksi ASI

\section{HYPNOBREASTFEEDING EXPLANATION AND TRAINING TO BREASTFEEDING MOTHERS IN INCREASING BREAST MILK PRODUCTION}

\begin{abstract}
Breast milk is a nutrient needed in the process of growth and development of infants which is monitored through weight gain according to the growth and development curve. If the milk production is sufficient, it can lead the baby to get exclusive breastfeeding. The percentage of exclusive breastfeeding is still low. The coverage of infants receiving exclusive breastfeeding in North Sumatra Province is $12.4 \%$, still below the national target of $80 \%$. The main reason for the failure of exclusive breastfeeding is the low milk production. Breast milk production is influenced by the hormones prolactin and oxytocin which are strongly influenced by the mother's psychological condition. The more calm and confident the mother is, the more these two hormones are produced. Psychological factors affect $70 \%$ of breast milk production. Hypnobreastfeeding is a natural effort to use subconscious energy by entering positive affirmative sentences so that the mother is relaxed and able to produce enough milk. Community service aims to provide counseling and training on Hypnobreastfeeding to 19 breastfeeding mothers in increasing breast milk production in Hamlet III and V, Namo Bintang Village, Pancur Batu District, Deli Serdang Regency. After the counseling, there was an increase in the knowledge of mothers in the good category $52.6 \%$ where previously $68.4 \%$ knowledge in the less category. And after 2 weeks of mothers doing hypnobreastfeeding, there was an increase in the baby's average weight of 339.4 gr. Relaxation that is done regularly is able to balance hormone and supports milk production and forms a positive mindset and calm for breastfeeding, so that mothers can enjoy breastfeeding well.
\end{abstract}

Keywords: Hypnobreastfeeding, Breast milk production. 


\section{Pendahuluan}

Bayi merupakan generasi penerus bangsa yang harus sehat dan terpenuhi gizinya, melalui pemberian Air Susu Ibu (ASI). ASI merupakan makanan pertama, utama dan terbaik bagi bayi yang bersifat alamiah karena mengandung berbagai zat gizi yang dibutuhkan dalam proses pertumbuhan dan perkembangan bayi. (Prasetyono, 2012)

ASI mengandung bermacam-macam zat anti baik yang seluler maupun yang humoral, sehingga mortalitas dan morbiditas neonatus yang minum ASI lebih rendah dari pada yang minum susu formula. Kebutuhan nutrisi bayi dapat terpenuhi apabila produksi ASI dapat memenuhi kebutuhan bayi, dengan penambahan berat badan sesuai kurva dalam tumbuh kembang bayi. Apabila produksi ASI cukup dapat menghantar bayi mendapatkan ASI Eksklusif (Astutik, 2016)

Persentase pencapaian pemberian ASI Eksklusif masih rendah. Cakupan bayi yang mendapat ASI Eksklusif sampai 6 bulan di Indonesia sebesar 29,5\% dan bayi yang mendapat ASI Eksklusif 0-5 bulan sebesar 54\%. Provinsi Sumatera Utara, untuk cakupan bayi yang mendapat ASI Eksklusif sampai 6 bulan sebesar $12,4 \%$ dan bayi yang mendapat ASI Ekslusif 0-5 bulan sebesar $46,8 \%$. Hal ini masih di bawah target nasional pada tahun 2016 yaitu sebesar 80\% (Kemenkes RI, 2017)

Beberapa faktor yang mempengaruhi pemberian ASI Eksklusif, diantaranya adalah faktor psikologis, saat persalinan, alat kontrasepsi, pola makan, konsumsi obat-obatan dan frekuensi menyusui. Alasan utama yang menjadi penyebab kegagalan pemberian ASI Eksklusif adalah produksi ASI yang sedikit. Produksi ASI dipengaruhi oleh hormon prolaktin dan oksitosin. Produksi kedua hormon ini sangat dipengaruhi oleh kondisi psikologis ibu, semakin ibu tenang dan percaya diri, maka hormon prolaktin dan oksitosin semakin banyak diproduksi. Faktor psikologis sangat berpengaruh besar terhadap produksi ASI karena pengeluaran ASI dari payudara lebih lancar saat ibu rileks dan nyaman. Faktor psikologis berpengaruh 70\% terhadap produksi ASI (Werdayanti,Rina. 2013)

Ibu yang mengalami stress, cemas, khawatir dan tidak percaya diri untuk dapat menyusui bahkan merasa ASI nya tidak cukup dapat menyebabkan produksi ASI yang sedikit. Oleh karena itu perlu adanya stimulus untuk membuat ibu tetap rileks, percaya diri sehingga dapat memperlancar produksi ASI terutama pada hari awal menyusui. Salah satu solusi yang dapat membantu mengatasi hambatan produksi ASI yang sedikit dalam pemberian ASI Eksklusif adalah hypnobreastfeeding (Kamariyah,N. 2014)

Hypnobreastfeeding adalah upaya alami menggunakan energi bawah sadar agar proses menyusui berjalan dengan aman dan lancar yang dilakukan dengan cara memasukkan kalimatkalimat afirmasi atau sugesti positif disaat ibu dalam keadaan sangat rileks atau sangat berkonsentrasi pada suatu hal/keadaan hypnosis sehingga ibu dapat menghasilkan ASI yang mencukupi untuk kebutuhan tumbuh kembang bayi. Relaksasi dalam hypnobreastfeeding dalam masa menyusui lebih difokuskan dengan sugesti- 
sugesti positif yang mengarah pada kenyamanan bayi dan ibu dalam proses menyusui, berbagi kasih sayang kepada bayi dengan memberikan ASI secara aman, nyaman dan tenang (Endah,Asri.dkk, 2014).

\section{Metode Pelaksanaan}

Pengabdian masyarakat ini bertujuan untuk memberikan pelatihan dan keterampilan kepada ibu-ibu yang sedang menyusu di Dusun III dan V Desa Namo Bintang agar dapat ditingkatkan pengetahuan dan keterampilannya tentang hypnobreastfeeading sebagai salah satu solusi yang dapat membantu mengatasi hambatan produksi ASI melalui pemberian stimulus untuk membuat ibu tetap rileks, nyaman dan percaya diri untuk dapat menyusui sehingga meningkatkan motivasi ibu untuk tetap memberikanASI Eksklusif. Produksi ASI dipengaruhi oleh hormon prolaktin dan oksitosin dimana produksi kedua hormon ini sangat dipengaruhi oleh kondisi psikologis ibu, semakin ibu tenang dan percaya diri, maka hormon prolaktin dan oksitosin semakin banyak diproduksi. Penambahan pruduksi ASI dapat dievaluasi melalui pemantauan terhadap berat badan bayi

Realisasi pemecahan masalah yang dilakukan adalah dengan melakukan serangkaian kegiatan :

1. Mendata semua ibu-ibu menyusu secara eksklusif di Dusun III dan V Desa Namo Bintang.

2. Kepada 19 ibu menyusu tersebut dikomunikasikan maksud dan tujuan dilakukan pengabdian masyarakat dan diminta kesediaannya untuk ikut serta dalam kegiatan tersebut.

3. Mengundang ibu menyusu dalam kegiatan penyuluhan tentang hypnobreastfeeding, dimana sebelum dan setelah penyuluhan dilakukan pengukuran pengetahuan.

4. Langkah selanjutnya selama dua kali pertemuan kepada ibu menyusu dilakukan pelatihan hypnobreastfeeding, sebelumnya dilakukan penimbangan berat badan (BB) bayi untuk mengetahui BB awal bayi.

5. Kemudian dilanjutkan dengan kegiatan observasi sebagai monitoring pelaksanaan hypnobreastfeeding oleh ibu secara mandiri dan kegiatan evaluasi dengan melakukan penimbangan $\mathrm{BB}$ bayi sebagai monitoring keberhasilan hypnobreastfeeding dalam meningkatkan produksi ASI melalui penambahan BB bayi.

Khalayak sasaran dan alat yang digunakan adalah sebagai berikut:

a. Khalayak Sasaran

Khalayak sasaran dalam kegiatan pengabdian masyarakat ini adalah ibu-ibu menyusu secara eksklusif yang berdomisili di Dusun III dan V Desa Namo Bintang Kecamatan Pancur Batu sebanyak 19 orang dengan usia bayi $\leq 6$ bulan.

b. Alat Yang Digunakan Metode penyampaian materi dilakukan dengan ceramah dan demonstrasi dengan menggunakan alat-alat sebagai berikut : LCD, laptop, leafled, headset, speaker, CD dan timbangan BB bayi. 
Metode Pengabdian yang dilakukan adalah sebagai berikut:

a. Kepada sebanyak 19 orang ibu menyusu secara eksklusif yang ada di Dusun III dan V Desa Namo Bintang Kecamatan Pancur Batu Kabupaten Deli Serdang dilakukan penyuluhan dan pelatihan tentang hypnobreastfeeding.

b. Selain penyuluhan dan pelatihan, dilakukan juga penimbangan $\mathrm{BB}$ bayi sebelum dan setelah pelatihan serta dilakukan pengukuran pengetahuan ibu menyusu tentang hypnobreastfeeding dan ASI dengan menggunakan kuesioner.

Keterkaitan Poltekkes Kemenkes Medan melalui Jurusan Kebidanan Medan sebagai mitra kerja dengan Kepala Desa Namo Bintang Kecamatan Pancur Batu Kabupaten Deli Serdang, memberikan rekomendasi untuk memberikan pelatihan kepada ibu-ibu yang sedang menyusui yang berada di daerah tersebut.

Pelaksanaan pengabdian masyarakat dilakukan pada bulan Juli sampai Agustus 2019 dengan tahap kegiatan sebagai berikut:

1. Tanggal 28 Agustus 2019; Peserta sebanyak 19 orang ibu menyusu secara eksklusif dilakukan pengukuran pengetahuan menggunakan kuesioner, kemudian dilanjutkan dengan kegiatan penyuluhan tentang hypnobreastfeeding ( 2 orang team turun ke lapangan)

2. Tanggal 3 \& 4 Agustus 2019, Peserta sebanyak 19 orang ibu menyusu secara eksklusif dilakukan pelatihan hypnobreastfeeding, sebelumnya dilakukan penimbangan $\mathrm{BB}$ sebagai $\mathrm{BB}$ awal bayi orang team turun ke lapangan)

3. Tanggal $10 \& 11$ Agustus 2019, dilakukan observasi sebagai monitoring pelaksanaan hypnobreastfeeding yang dilakukan ibu menyusu secara mandiri ( 2 orang team turun ke lapangan)

4. Tanggal 17 Agustus 2019, dilakukan evaluasi keberhasilan kegiatan hypnobreastfeeding dalam meningkatkan produksi ASI dengan menimbang BB bayi sekaligus mengukur pengetahuan ibu.

Evaluasi dilaksanakan dua minggu setelah melakukan kegiatan penyuluhan dan pelatihan. Evaluasi dilakukan tanggal 17 Agustus 2019, yaitu melakukan pengukuran pengetahuan ibu tentang hypnobreastfeeding dan ASI melalui kuesioner dan mengukur BB badan bayi untuk mengetahui penambahan $\mathrm{BB}$ bayi setelah dua minggu ibu melakukan hypnobreastfeeding.

\section{Hasil}

Setelah dilakukan penyuluhan dan pelatihan kepada 19 ibu-ibu menyusu, maka diperoleh hasil sebagai berikut:

Tabel 1. Tingkat Pengetahuan Ibu-Ibu Menyusu Di Dusun III Dan V Desa Namo Bintang Tentang Hypnobreastfeeding Dan ASI Sebelum Dan Setelah Pelatihan

\begin{tabular}{cccccc}
\hline \multirow{2}{*}{ No Kategori } & \multicolumn{4}{c}{ Pengetahuan } \\
\cline { 3 - 6 } & & \multicolumn{2}{c}{ Sebelum } & \multicolumn{3}{c}{ Setelah } \\
\cline { 3 - 5 } & & F & $\%$ & f & $\%$ \\
\hline 1 & Baik & - & & 10 & 52.6 \\
\hline 2 & Cukup & 6 & 31.6 & 7 & 36.8 \\
\hline 3 & Kurang & 13 & 68.4 & 2 & 10,6 \\
\hline & Total & 19 & 100 & 19 & 100 \\
\hline
\end{tabular}

Tabel 1 menunjukkan bahwa terdapat peningkatan pengetahuan ibu menyusu, dimana 
sebelum dilakukan pelatihan mayoritas pengetahuan pada kategori kurang (68.4\%), dan setelah dilakukan pelatihan mayoritas menjadi kategori baik (52.6\%)

Tabel 2. Rerata BB bayi IbuMenyusu Di Dusun III \& V Desa Namo Bintang sebelum dan setelah Pelatihan

\begin{tabular}{|c|c|c|c|c|c|c|}
\hline \multicolumn{2}{|c|}{ Variabel } & $\mathrm{n}$ & Rerata & Min & Max & $\begin{array}{r}\text { Selisih } \\
\text { Rerata } \\
\text { BB (gr) }\end{array}$ \\
\hline \multirow{2}{*}{ BB } & $\begin{array}{c}\text { Sebelum } \\
\text { Pelatihan }\end{array}$ & 19 & 5981,6 & 4500 & 7600 & \multirow{2}{*}{339,4} \\
\cline { 2 - 5 } & $\begin{array}{c}\text { Sesudah } \\
\text { Pelatihan }\end{array}$ & 19 & 6321 & 4850 & 7900 & \\
\hline
\end{tabular}

Tabel 2 menunjukkab bahwa terdapat peningkatan rerata $\mathrm{BB}$ bayi dari ibu menyusu setelah 2 minggu ibu melakukan hypnobreastfeeding, dimana terdapat selisih peningkatan rerata BB bayi sebelum dan setelah dilakukan pelatihan sebesar 339,4 gr.

\section{Pembahasan}

Hasil pengabdian setelah diberikan pelatihan terhadap responden (Tabel 1) dimana sebelumnya kategori pengetahuan mayoritas kurang (68.4\%), berubah menjadi kategori baik (52.6\%).

Salah satu dari tingkatan pengetahuan adalah tahu yang diartikan sebagai mengingat suatu materi yang telah dipelajari sebelumnya. Pada kegiatan pengabdian masyarakat ini terlihat bahwa ibu menyusu telah mengetahui tentang hypnobreastfeeding salah satu solusi yang dapat membantu mengatasi hambatan produksi ASI melalui pemberian stimulus untuk membuat ibu tetap rileks, nyaman dan percaya diri untuk dapat menyusui sehingga meningkatkan motivasi ibu untuk tetap memberikanASI Eksklusif.
Perlu diketahui bahwa adanya peningkatan pengetahuan responden karena ditindaklanjuti dengan kegiatan intervensi yang dimulai dengan penyuluhan selanjutnya dilakukan pelatihan tentang hypnobreastfeeding.

Hipnosis pada ibu menyusui disebut dengan hypnobreastfeeding. Hypnobreastfeeding adalah upaya alami menggunakan energi bawah sadar agar proses menyusui berjalan dengan aman dan lancar yang dilakukan dengan cara memasukkan kalimat-kalimat afirmasi atau sugesti positif disaat ibu dalam keadaan sangat rileks atau sangat berkonsentrasi pada suatu hal/keadaan hypnosis sehingga ibu dapat menghasilkan ASI yang mencukupi untuk kebutuhan tumbuh kembang bayi. Relaksasi dalam hypnobreastfeeding dalam masa menyusui lebih difokuskan dengan sugesti-sugesti positif yang mengarah pada kenyamanan bayi dan ibu dalam proses menyusui, berbagi kasih sayang kepada bayi dengan memberikan ASI secara aman, nyaman dan tenang (Aini, Y, Hadi, 2017)

Ibu yang mengalami stress, cemas, khawatir dan tidak percaya diri untuk dapat menyusui bahkan merasa ASI nya tidak cukup dapat menyebabkan produksi ASI yang sedikit. Oleh karena itu perlu adanya stimulus untuk membuat ibu tetap rileks, percaya diri sehingga dapat memperlancar produksi ASI.

Penelitian telah menunjukkan bahwa relaksasi yang dilakukan berulang-ulang secara rutin selama 20 menit akan dapat meningkatkan produksi ASI sebesar 63\%. Keadaan pikiran seorang ibu dapat mempengaruhi laktasi, terutama let-down refleks. Stres, kegelisahan dan 
kelelahan dapat menghambat suplai ASI sehingga latihan relaksasi sangat bermanfaat baik secara fisik maupun psikologis untuk ibu dan bayi.Stres yang dialami oleh ibu sesaat setelah setelah bayi lahir, serta tidak adanya dukungan untuk dapat menyusui semakin meningkatkan sekresi hormon kortisol (hormon yang berpengaruh terhadap stres) sehingga menyebabkan ASI keluar dengan tidak lancer (Aini, Y, Hadi, 2017)

Alasan utama yang menjadi penyebab kegagalan pemberian ASI Eksklusif adalah produksi ASI yang sedikit. Produksi ASI dipengaruhi oleh hormon prolaktin dan oksitosin. Produksi kedua hormon ini sangat dipengaruhi oleh kondisi psikologis ibu, semakin ibu tenang dan percaya diri, maka hormon prolaktin dan oksitosin semakin banyak diproduksi. Faktor psikologis sangat berpengaruh besar terhadap produksi ASI karena pengeluaran ASI dari payudara lebih lancar saat ibu rileks dan nyaman. Faktor psikologis berpengaruh $70 \%$ terhadap produksi ASI (Werdayanti,Rina. 2013).

Hasil penelitian yang dilakukan Julietta dkk (2018) di Desa Perlis Kab. Langkat bahwa hypnobreastfeeding berpengaruh terhadap peningkatan produksi ASI pada ibu menyusui dimana rerata peningkatan produksi ASI kelompok yang tidak diberi hypnobreastfeeding sebesar 79,69 ml sedangkan rerata kelompok yang diberi perlakuan $93,94 \mathrm{ml}$ sehingga terdapat selisih rerata peningkatan produksi ASI sebesar 14,25 ml. Demikian juga hasil penelitian oleh Rismahara dkk ( 2018) yang berjudul Efektifitas hypnobreastfeeding pada ibu menyusui terhadap kecukuoan ASI pada bayi usia $\leq 3$ bulan di PMB
Risma dan PMB Sri Armila Deli Serdang, bahwa rerata peningkatan kenaikan berat badan bayi dari ibu yang diberi perlakuan hypnobreastfeeding lebih besar dibandingkan dengan kelompok ibu yang tidak diberi perlakuan hypnobreastfeeding.

Pada kegiatan pengabdian ini juga ditemukan hasil bahwa terdapat peningkatan rerata $\mathrm{BB}$ bayi dari ibu menyusu di Dusun III dan V Desa Namo Bintang Kec.Pancur Batu Kab.Deli Serdang setelah 2 minggu ibu melakukan hypnobreastfeeding, dimana terdapat selisih peningkatan rerata BB bayi sebelum dan setelah dilakukan pelatihan sebesar 339,4 gr.

Teknik relaksasi hypnobreastfeeding adalah cara atau metode terbaru yang sangat baik untuk membangun niat positif dan motivasi dalam menyusui serta mampu memaksimalkan kuantitas dan kualitas ASI. Relaksasi yang dilakukan dengan teratur mampu menyeimbangkan kadar hormone setelah melahirkan, dan mendukung produksi ASI serta membentuk pola pikir yang positif dan ketenangan untuk menyusui, sehingga ibu dapat menikmati proses menyusui dengan baik (Kamariyah,N. 2014).

\section{Kesimpulan}

Berdasarkan hasil penelitian yang dilakukan di dusun III \& V Desa Namo Bintang Kecamatan Pancur batu kabupaten Deli Serdang dapat disimpulkan bahwa Terjadi peningkatan pengetahuan ibu-ibu menyusu di Dusun III dan V Desa Namo Bintang Kec. Pancur Batu Kab. Deli Serdang setelah dilakukan penyuluhan dan pelatihan, mayoritas dengan kategori pengetahuan baik (52.6\%). Terdapat peningkatan rerata BB bayi dari ibu menyusu setelah 2 
minggu ibu melakukan hypnobreastfeeding, dimana terdapat selisih peningkatan rerata $\mathrm{BB}$ bayi sebelum dan setelah dilakukan pelatihan sebesar 339,4 gr.

\section{Saran}

Kegiatan pengabdian masyarakat seperti ini perlu dikembangkan di dusun lain sehingga seluruh ibu menyusu mengetahui bahwa hypnobreastfeeding merupakan salah satu solusi dalam meningkatkan produksi ASI.Perlu dilatih kader sebagai tutor sehingga setiap ibu menyusu dapat diajari tentang hypnobreastfeeding yang merupakan salah satu cara meningkatkan produksi ASI dan memberi otivasi bagi ibu menyusu untuk tetap memberikan ASI Eksklusif.

\section{Daftar Pustaka}

Aini, Y, Hadi, Sri, R, Noor, P, Donny, K. (2017). Effect of combination of oxytocin massage and hypnobreastfeeding on uterine involution and prolactin levels in postpartum mothers. Belitung Nursing Journal. Indonesia.

Astutik Reni Yuli. (2016). Payudara dan Laktasi. Salemba Medika.

Endah, A. dkk. (2014). Hypnobreastfeeding Untuk Keberhasilan Pemberian AsiEksklusif Di Rs X. STIKes Santo Borromeus.

Hutabarat Julietta,, Sartini Bangun., T. S. (2018). Pengaruh hypnobraesfeeding terhadap peningkatan produksi ASI pada ibu menyusui di desa Perlis Kec.tangkahan durian Kab. Langkat.(Hasil penelitian).

Kamariyah, N. (2014). Kondisi Psikologi Mempengaruhi Produksi Asi Ibu Menyusui di Bps Aski Pakis SidoKumpul Surabaya.

Kemenkes RI. (2017). Profil Kesehatan Indonesia 2016.

http://www.depkes.go.id/resources/download/pu sdatin/profi-kesehatan-indonesia/ ProfilKesehatan-Indonesia-2016
Lubis, Rismahara., Y. S. (2018). Efektifitas hypnobreastfeeding pada ibu menyusui terhadap kecukuoan ASI pada bayi usia $\leq 3$ bulan di PMB Risma dan PMB Sri Armila Deli Serdang.

Prasetyono Dwi Sunar. (2012). Buku Pintar ASI Eksklusif. DIVA Press. TIM.

Werdayanti, Rina. (2013). Welcome to the exclusive Club Asi Eksklusif. Familia. 